\title{
KONVERSI CITRA KARTU NAMA KE TEKS MENGGUNAKAN TEKNIK OCR DAN JARO-WINKLER DISTANCE
}

\author{
Dewinta Zulhida Putri ${ }^{1)}$, Diyah Puspitaningrum²), Yudi Setiawan ${ }^{3)}$

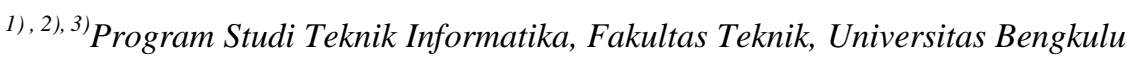 \\ JL. WR. Supratman, Kandang Limun, Kota Bengkulu 38371 A \\ Email :dewintaputri23@gmail.com ${ }^{1)}$,diyahpuspitaningrum@gmail.com ${ }^{2)}$,ysetiawan@unib.ac.id ${ }^{3)}$
}

\begin{abstract}
Abstrak
Kartu nama memiliki data yang dapat disimpan ke dalam database kontak smartphone, seperti nama, jabatan, instansi, nomor ponsel, nomor telepon, nomor fax, alamat pertama, alamat kedua dan e-mail. Penelitian ini bertujuan membangun aplikasi yang dapat memindahkan data kartu nama dari foto ke database kontak smartphone dengan konversi citra kartu nama ke teks dengan melakukan ekstraksi teks dan pengelompokan data. Algoritma yang digunakan untuk ekstraksi teks adalah Optical Character Recognition (OCR). Teks yang sudah diekstraksi kemudian akan dikelompokan menggunakan algoritma Jaro-Winkler Distance. Pengujian sistem yang dilakukan dengan menggunakan data kartu nama yang beralamat di Provinsi Bengkulu sebanyak 50 buah dengan berbagai jenis tulisan dan background. Aplikasi dirancang dengan Bahasa pemrograman Java dengan IDE Android Studio dan library Tesseract. Hasil akhir dari sistem adalah data kontak yang tersimpan di database smartphone. Hasil uji coba sistem yang dilakukan didapatkan nilai akurasi rata-rata dari lima kali percobaan adalah $76 \%$ untuk data nama, 74\% untuk data jabatan, 56\% untuk data instansi, $82 \%$ untuk data nomor ponsel, $86 \%$ untuk data nomor telepon, $78 \%$ untuk data alamat, dan $88 \%$ untuk data e-mail.
\end{abstract}

Kata Kunci : Konversi Citra, Ekstraksi Teks, Kartu Nama, Optical Character Recognition (OCR), JaroWinkler Distance

\section{Pendahuluan}

\section{Latar Belakang}

Kartu nama merupakan bagian penting yang sulit dipisahkan dari kehidupan seseorang, terutama orangorang yang menggeluti dunia bisnis. Kartu nama berisikan identitas seseorang agar orang lain dapat menghubunginya untuk berkomunikasi lebih lanjut di kemudian hari. Kartu nama biasanya berisi nama, nomor-nomor yang dapat dihubungi, alamat perusahaan. Kartu nama juga dapat berisikan informasi lainnya sesuai dengan identitas yang ingin diberikan oleh pemilik kartu nama. Saat menerima kartu nama dari orang lain, beberapa penerima akan menyimpan kartu nama tersebut di dalam saku, dompet, atau tempat khusus kartu nama. Lalu kemudian kartu nama tersebut akan kembali dicari saat akan menghubungi seseorang yang bersangkutan. Risiko kehilangan kartu nama merupakan batasan dari cara tersebut, sehingga beberapa orang akan langsung memindahkan informasi pribadi yang ada di kartu nama tersebut ke database handphone atau smartphone agar dapat lebih mudah dicari.

Aktivitas pemindahan data ini tentu menyita waktu dan ketelitian dari penerima kartu nama. Padahal kecanggihan teknologi dapat dimanfaatkan untuk mengatasi kekurangan ini sehingga membuat pemindahan data dari kartu nama ke database penerima kartu nama menjadi lebih mudah dan cepat. Salah satu teknologi yang dapat dimanfaatkan adalah dengan melakukan ekstraksi teks yang akan mengkonversi citra kartu nama ke teks. Kartu nama yang telah difoto oleh penerima kartu nama dapat diekstrak langsung menjadi teks sehingga data langsung dapat disimpan tanpa diketik ulang. Kartu nama yang sebagian besar terdiri dari teks dapat dikonversi menjadi teks dengan menggunakan Optical Character Recognition (OCR).

OCR merupakan teknologi yang memungkinkan untuk mengenali karakter melalui mekanisme optik secara otomatis. Diibaratkan pada manusia, mata merupakan mekanisme optik. OCR adalah teknologi yang berfungsi seperti kemampuan manusia membaca. Meskipun OCR tidak mampu bersaing dengan kemampuan membaca manusia. OCR dapat mengenali teks baik tulisan tangan maupun hasil cetakan [1].

Setelah diekstrak maka teks tersebut haruslah dikelompokkan berdasarkan nama, alamat, nomor telepon, nomor ponsel, dan data lainnya yang ingin disimpan. Data dikelompokkan berdasarkan ciri-ciri yang telah ditentukan, misalnya alamat pasti mengandung data jalan. Ini berarti diperlukan algoritma pencocokan string untuk mengelompokan data-data tersebut. Salah satu algoritma yang dapat digunakan untuk mencocokan string adalah Jaro-Winkler Distance. Jaro-Winkler Distance sangat cocok dan memberikan hasil terbaik pada pencocokan dua string singkat, misalnya nama orang [2].

Berdasarkan hal tersebut, maka penulis mengusulkan proposal penelitian untuk menciptakan aplikasi yang dapat melakukan Konversi Citra Kartu Nama Ke Teks Menggunakan Teknik Optical Character Recognition 
(OCR) Dan Jaro-Winkler Distance dengan pengimplementasi ada smartphone.

\section{Tujuan}

Penelitian ini diharapkan dapat menghasilkan aplikasi yang akan memudahkan pemindahan dan pengelompokan data dari kartu nama ke database kontak smartphone berdasarkan nama, alamat, nomor ponsel, nomor telepon, dan email.

\section{Metodologi Penelitian}

Pengumpulan data dalam penelitian ini menggunakan beberapa metode, yaitu:

1. Studi Pustaka

Studi pustaka dilakukan dengan mengumpulkan data dan informasi yang akan digunakan dalam perancangan dan pengembangan aplikasi ekstraksi teks dari foto kartu nama. Data yang digunakan diperoleh dari buku-buku, jurnal-jurnal, laporan penelitian, artikel ilmiah, skripsi, tesis, dan sumber tertulis lainnya yang berkaitan dengan kartu nama, Optical Character Recognition (OCR), JaroWinkler Distance, Data Flow Diagram (DFD), OpenCV, Android, dan basis data dengan SQLite.

\section{Dokumentasi}

Dokumentasi merupakan catatan peristiwa yang sudah lalu. Dokumentasi dapat berbentuk dokumen gambar, tulisan, atau karya-karya monumental dari seseorang. Penelitian ini menggunakan metode pengumpulan data dokumentasi yang menghasilkan dokumen foto-foto.

\section{Tinjauan Pustaka}

\section{Kartu Nama}

Kartu nama merupakan sebuah kartu yang berisikan informasi seseorang berupa nama, nama perusahaan, dan nomor telepon., terdapat beberapa tujuan seseorang memiliki dan memberikan kartu nama kepada yang lainnya, seperti:

a. Kartu nama yang dirancang dengan baik menandakan bahwa pemberinya merupakan seseorang yang bertanggungjawab dan mudah dijangkau.

b. Saat seseorang memasarkan dirinya dalam mencari pekerjaan, maka kartu nama "harus menjadi bagian integral dari gudang pemasaran." [3]

c. Kartu nama adalah bagian penting untuk menyampaikan citra professional [4].

\section{Konversi Citra ke Teks}

Citra juga dapat dikonversi menjadi bentuk teks dengan memanfaatkan proses pengenalani teks dari citra. Pengenalan teks adalah metode yang dikembangkan untuk membuat sistem yang mampu memberi pengertian atau deskripsi mengenai objek teks pada citra. Pengenalan teks merupakan bagian dari teknik analisa citra. Elemen dasar citra yang dianalisa pada teknik pengolahan teks adalah elemen bentuk. Proses pengenalan teks atau pendeteksian teks pada media gambar berarti sistem dapat mengenali/membaca suatu objek teks pada media gambar dan menulisnya ke bentuk string. String merupakan defenisi karakter berdasarkan kode ASCII [5].

String sering kita temui pada piranti lunak pengolah kata atau pada program penyunting teks. Teks pada media citra adalah bukan merupakan string, karena teks tersebut bukan merupakan perwakilan dari kode - kode ASCII, tapi merupakan objek yang terbentuk dari susunan piksel. Metode dasar yang digunakan untuk mengenali objek tersebut sebagai teks adalah dengan mencirikan bentuk dari karakter tersebut masing masing [5].

\section{Optical Character Recognition}

Optical Character Recognition (OCR) adalah proses yang dapat mengkonversi gambar yang berisikan teks menjadi karakter ASCII yang dapat dikenali oleh komputer. Berbagai pendekatan yang dapat digunakan pada Optical Character Recognition, yaitu matrix matching, fuzzy logic, ekstraksi fitur, analisa struktural, dan jaringan syaraf [1].

\section{Tesseract}

Tesseract adalah mesin OCR open-source yang dikembangkan di HP (Hewlett-Packard) antara tahun 1984 dan 1994. Tesseract muncul sebagai projek penelitian $\mathrm{PhD}$ di HP Labs, Bristol yang tersedia di http://code.google.com/p/tesseract-ocr [6]. Tahapan proses Optical Character Recognition oleh Tesseract adalah:
a. Page Layout Analysis
b. Blob Finding
c. Find Text Line and Words
d. Recognition Word Pass 1
e. Recognition Word Pass 2
f. Fuzzy Space and $x$-height Fix-up

\section{Jaro-Winkler Distance}

Jaro-Winkler distance adalah Jaro distance dengan Winkler modification. Jaro distance digunakan untuk komputasi antara dua string (A dan B) dan berdasarkan pencocokan dan transposisi karakter [7]. Tahapan algoritma ini adalah:

a. Menghitung panjang string,

b. Menemukan jumlah karakter yang sama di dalam dua string

c. Menemukan jumlah transposisi

d. Menghitung jarak (dj) antara dua string yaitu s1 dan s2 dengan menggunakan rumus 2.1.

$\mathrm{dj}=1 / 3 \times(\mathrm{m} /|\mathrm{s} 1|+\mathrm{m} /|\mathrm{s} 2|+(\mathrm{m}-\mathrm{t}) / \mathrm{m})$ Keterangan:

$\mathrm{m}=$ jumlah karakter yang sama persis

$|\mathrm{s} 1|$ = panjang string 1

$|\mathrm{s} 2|=$ panjang String 2

$\mathrm{t}=$ jumlah transposisi

e. Jaro-Winkler distance (dw) akan didapatkan dengan persamaan 2.2 .

$d w=d j+(\operatorname{lp}(1-d j))$

dimana :

$\mathrm{dj}=$ Jaro distance untuk strings s1 dan string s2 
1 = panjang prefiks umum di awal string nilai maksimalnya 4 karakter (panjang karakter yang sama sebelum ditemukan ketidaksamaan max 4) $\mathrm{p} \quad=$ konstanta scaling factor. Nilai standar untuk konstanta ini menurut Winkler adalah $\mathrm{p}=$ 0,1 .

\section{Pembahasan}

\section{A. Aplikasi Pemindai Kartu Nama}

Aplikasi ini terdiri dari tiga halaman, yaitu halaman utama, halaman proses, dan halaman simpan. Halaman yang akan melakukan segala proses utama dalam aplikasi tersebut, yaitu OCR dan pengelompokan data. Halaman proses dapat dilihat pada Gambar 1. Di dalam halaman proses terdapat tiga tombol, yaitu tambah, proses dan next. Tombol tambah dapat dipilih pengguna untuk menambahkan foto yang ingin diproses dan diambil datanya. Saat memilih tombol tambah pengguna akan diminta untuk memilih sumber foto yang ingin diproses, yaitu melalui kamera atau galery smartphone pengguna. Setelah memilih foto kartu nama yang ingin diproses, foto tersebut kemudian akan ditampilkan di bagian tengah halaman. Guna memproses foto tersebut, pengguna dapat memilih tombol proses. Pertamatama aplikasi akan melakukan OCR terhadap foto tersebut dan mengambil bagian teksnya saja. Setelah teks didapatkan, lalu hasil OCR tersebut akan dibersihkan dengan membuang tanda baca yang tidak diinginkan.

Setelah teks hasil OCR dibersihkan, selanjutnya data tersebut akan dikelompokan menjadi nama, alamat, nomor ponsel, nomor telepon dan email menggunakan Jaro-Winkler Distance. Hasil dari pengelompokan tersebut akan disimpan di dalam database. Semua proses ini akan dilakukan ketika pengguna memilih tombol proses. Di bagian bawah aplikasi terdapat tombol next yang akan membawa pengguna ke halaman berikutnya, yaitu halaman simpan.

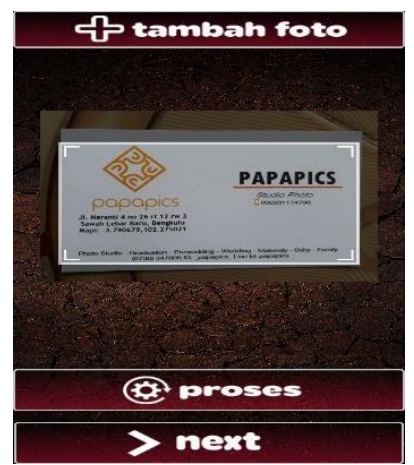

Gambar 1. Halaman Proses Aplikasi

\section{B. Pengujian Black Box Sistem}

Metode ini berhasil melakukan pengecekan terhadap fungsi yang tidak benar atau hilangm kesalahan antarmuka, kesalahan dalam struktur data atau akses database eksternal, dan kesalahan kinerja. Pada pengujian ini telah didapatkan hasil $100 \%$ kebenaran sistem, mulai dari tidak ada kesalaham antar muka, sistem dan lain sebagainya.

\section{Pengujian Optical Character Recogition}

Data uji coba yang digunakan sebanyak 50 data. Pengujian dilakukan sebanyak 5 kali. Hasil dari pengujian OCR terhadap kartu nama dapat dilihat pada Tabel 1 untuk kartu nama Gambar 2.

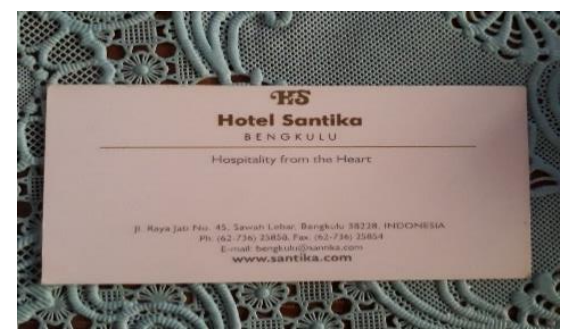

Gambar 2. Contoh Data Kartu Nama

Hasil ekstraksi menunjukan library Tesseract sudah dapat mengekstraks teks dari citra kartu nama. Namun, hasil menunjukan terdapat karakter-karakter yang tidak terdapat di kartu nama juga ikut terkestraksi. Banyaknya huruf-huruf atau karakter yang tidak terdapat di kartu nama tapi juga ikut diekstraksi disebabkan oleh adanya figure atau grafik di dalam kartu nama tersebut yang dapat menghasilkan teks atau karater kacau pada bagian tersebut [8].

Terlihat hasil yang dihasilkan menjadi satu kolom dari kartu nama yang sebelumnya terdiri dari dua kolom. Hal ini karena library yang digunakan, yaitu Tesseract tidak mempunyai analisis layout untuk kolom, sehingga tidak dapat mendeteksi gambar yang multikolom [8].

Pada proses ekstraksi di Tabel 1 masih terdapat beberapa karakter yang berbeda antara data asli dengan data hasil ekstraksi. Perbedaan ini dikarenakan Tesseract gagal mengenali karakter yang dimaksudkan. Kegagalan ini dapat disebabkan oleh banyaknya noise yang terdapat di dalam gambar, sehingga proses analisis connected component memberikan hasil yang salah. Analisis connected component merupakan proses awal dari Tesseract Tess-Two sehingga jika proses ini mengalami kegagalan, maka akan mempengaruhi proses berikutnya [6].

Percobaan yang dilakukan selama lima kali terhadap masing-masing kartu nama dapat menghasilkan data hasil ekstraksi yang berbeda setiap kali proses ekstraksi dilakukan. Tapi, hal ini tidak menjamin semakin lama hasilnya semakin bagus karena hasil terbaik tidak pada 
percobaan terakhir, tapi dapat terjadi pada percobaan kedua atau ketiga. Hal ini karena Tesseract dapat mengenali teks dengan baik pada percobaan kedua atau ketiga. Setelah itu hasil dari proses Tesseract dapat sama dengan proses sebelumnya atau menjadi lebih buruk. Ini dikarenakan analisis tata layout Tesseract yang buruk [9].

Tabel 1. Data Hasil Ekstraksi

\begin{tabular}{|c|c|c|c|}
\hline No & $\begin{array}{l}\text { Data Asli Pada } \\
\text { Kartu Nama }\end{array}$ & $\begin{array}{c}\text { Hasil } \\
\text { Percobaan 1 }\end{array}$ & $\begin{array}{c}\text { Hasil } \\
\text { Percobaan } 2\end{array}$ \\
\hline 1. & $\begin{array}{l}\text { HOTEL } \\
\text { SANTIKA } \\
\text { BENGKULU } \\
\text { Hospitality from } \\
\text { the Heart } \\
\text { Jl. Raya Jati No. } \\
\text { 45, Sawah } \\
\text { Lebar, Bengkulu } \\
\text { 38228, } \\
\text { INDONESIA } \\
\text { Ph. (62-736) } \\
\text { 25858, Fax: (62- } \\
\text { 736) 25854 } \\
\text { E-mail } \\
\text { bengkulu@ santi } \\
\text { ka.com } \\
\text { www.santika.co }\end{array}$ & $\begin{array}{l}\text { Hotel Santlka } \\
\text { B E N G K U L } \\
\text { U } \\
\text { Hospitality from } \\
\text { the Heart } \\
\text { ]t. Raya Jan No. } \\
\text { 45, Sawah } \\
\text { Lebar. } \\
\text { Bengkulu } \\
\text { 38228, } \\
\text { INDONESIA } \\
\text { Ph. (62-736) } \\
\text { 25858. } \\
\text { (62736) 25854 } \\
\text { Email } \\
\text { bengkulu@ sann } \\
\text { ka.com } \\
\text { www.santika.co } \\
\text { m }\end{array}$ & $\begin{array}{l}\text { Hotel Santlka } \\
\text { B E N G K U } \\
\text { L U } \\
\text { Hospitality } \\
\text { from the Heart } \\
\text { ]t. Raya jam } \\
\text { No. 45, Sawah } \\
\text { Lebar. } \\
\text { Bengkulu } \\
\text { 38228, } \\
\text { INDONESIA } \\
\text { Ph. (62-736) } \\
25858 . \\
\text { (62-736) Fax } \\
25854 \\
\text { Email } \\
\text { bengkulu@ san } \\
\text { tlka.com } \\
\text { www.santika.c } \\
\text { om }\end{array}$ \\
\hline
\end{tabular}

\begin{tabular}{|c|c|c|}
\hline $\begin{array}{c}\text { Hasil Percobaan } \\
3\end{array}$ & $\begin{array}{l}\text { Hasil Percobaan } \\
4\end{array}$ & $\begin{array}{l}\text { Hasil Percobaan } \\
5\end{array}$ \\
\hline Hotel Santlka & Hotel Santlka & Hotel Santlka \\
\hline B E N G K U L U & B E N G K U L U & B E N G K U L U \\
\hline Hospitality from & Hospitality from & Hospitality from \\
\hline the Heart & the Heart & the Heart \\
\hline ]t. Raya Jan No. & ]f. Raya Jatl No. & ]f. Raya Jatl No. \\
\hline 45, Sawah Lebar. & 45, Sawah Lebar. & 45, Sawah Lebar. \\
\hline $\begin{array}{l}\text { Bengkulu } 38228 \text {, } \\
\text { INDONESIA }\end{array}$ & $\begin{array}{l}\text { Bengkulu } 38228 \text {, } \\
\text { INDONESIA }\end{array}$ & $\begin{array}{l}\text { Bengkulu } 38228 \text {, } \\
\text { INDONESIA }\end{array}$ \\
\hline Ph. $\quad(62-736)$ & $(62736)$ & (62736) \\
\hline 25858. Fax & 25858. Fax & 25858. Fax \\
\hline $\begin{array}{l}(62736) 25854 \\
\text { Email }\end{array}$ & $\begin{array}{l}\text { (62736) } 25854 \\
\text { Emaii }\end{array}$ & $\begin{array}{l}\text { (62736) } 25854 \\
\text { Emaii }\end{array}$ \\
\hline bengkulu@sannka & bengkulu@sannka & bengkulu@sannka \\
\hline .com &. $\mathrm{com}$ & .com \\
\hline www.santika.com & www.santika.com & www.santika.com \\
\hline
\end{tabular}

\section{Pengujian Jaro Winkler}

Pengelompokan dilakukan dengan menghitung nilai Jaro-Winkler Distance setiap baris hasil ekstraksi dengan data pembanding yang terdapat di dalam database. Contoh perhitungannya dapat dilihat pada Tabel 2.

Tabel 2. Contoh perhitungan Jaro Distance

\begin{tabular}{|l|l|l|l|l|l|}
\hline No & \multicolumn{1}{|c|}{$\mathrm{s} 1$} & $\mathrm{~s} 2$ & $\mathrm{~m}$ & $\mathrm{~T}$ & \multicolumn{1}{c|}{$\mathrm{dj}$} \\
\hline 1 & $\begin{array}{l}62736 \\
=5\end{array}$ & $+62736=6$ & 5 & 0 & $\begin{array}{l}0,9444444 \\
44\end{array}$ \\
\hline 2 & $\begin{array}{l}62736 \\
=5\end{array}$ & $0736=4$ & 3 & 0 & 0,7833333 \\
33
\end{tabular}

Nilai string pertama didapat dari data hasil ekstraksi kartu nama. String pertama ini akan dibandingkan dengan nilai-nilai pembanding yang akan menjadi string 2. Nilai pembanding yang dibandingkan sebanyak empat nilai pembanding untuk ponsel, lima nilai pembanding untuk alamat, 18 nilai pembanding untuk perusahaan dan 28 nilai pembanding untuk nomor telepon berdasarkan ciri-ciri yang telah disebutkan pada bagian poin 4 .A.

Tabel 3. Contoh perhitungan JaroWinkler Distance

\begin{tabular}{|c|c|c|c|c|}
\hline No & $\mathrm{Dj}$ & $\mathrm{I}$ & $\mathrm{p}$ & $\mathrm{dw}$ \\
\hline 1 & 0,944444444 & 0 & 0,1 & 0,944444444 \\
\hline 2 & 0,783333333 & 0 & 0,1 & 0,783333333 \\
\hline 3 & $\sim$ & 0 & 0,1 & $\sim$ \\
\hline 4 & 0,633333333 & 0 & 0,1 & 0,633333333 \\
\hline 5 & $\sim$ & 0 & 0,1 & $\sim$ \\
\hline
\end{tabular}

Dilihat dari contoh perhitungan pada Tabel 3 dapat dilihat bahwa nilai Jaro-Winkler Distance terbesar adalah nilai untuk string pembanding ' +62736 ' dengan nilai 0,944444444. Jika nilai Jaro-Winkler Distance lebih besar dari 0.9 untuk string pembandin tertentu, maka data yang mengandung string pertama akan masuk ke kelompok data string pembanding tersebut, karena semakin mendekati nilai 1 maka semakin mirip kedua string tersebut [7]. Pada contoh perhitungan pada Tabel 2 dan 3 nilai Jaro-Winkler Distance terbesar merupakan milik string pembanding ' +62736 ' yang masuk ke ciri-ciri data telepon, sehingga data yang mengandung string pertama '62736' akan masuk ke data telepon. 


\begin{tabular}{|c|c|c|c|c|c|}
\hline 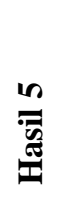 & ' & 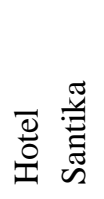 & ' & ' & 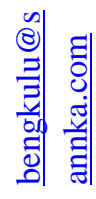 \\
\hline 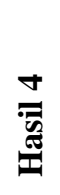 & 1 & 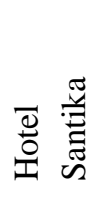 & ' & ' & 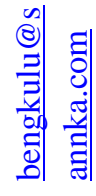 \\
\hline $\begin{array}{l}m \\
\stackrel{7}{5} \\
\frac{7}{\pi}\end{array}$ & ' & 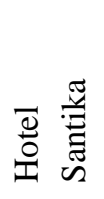 & ' & ' & 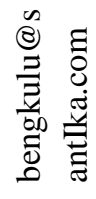 \\
\hline $\begin{array}{l}\mathrm{N} \\
\stackrel{7}{5} \\
\stackrel{5}{5}\end{array}$ & ' & 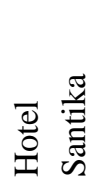 & ' & ' & 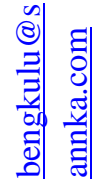 \\
\hline 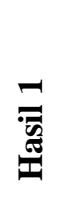 & ' & 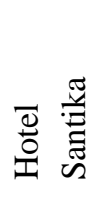 & ' & ' & 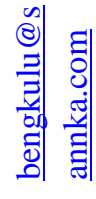 \\
\hline 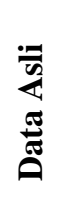 & 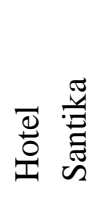 & 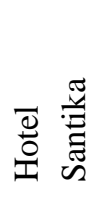 & ' & ' & 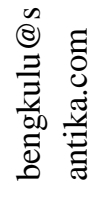 \\
\hline 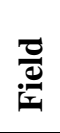 & $\begin{array}{l}\text { ్్̃ } \\
\text { z̆ }\end{array}$ & 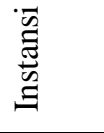 & 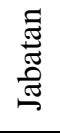 & 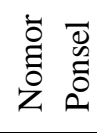 & $\sum_{\substack{\mid=\\
\tilde{I}}}^{\bar{\pi}}$ \\
\hline$\stackrel{\circ}{z}$ & - & $N$ & $m$ & $\nabla$ & $n$ \\
\hline
\end{tabular}

Berdasarkan data hasil pengelompokan pada tabel di atas Jaro-Winkler sudah dapat mengelompokan data kartu nama berupa nama, nomor ponsel, telepon 2/fax, email, alamat pertama, alamat kedua, jabatan dan instansi yang terdapat di dalam kartu nama. Namun, kesalahan masih ditemui pada bagian pengelompokan untuk kategori instansi dan jabatan. Kesalahan pengelompokan pada field instansi karena beberapa kartu nama menggunakan logo sebagai tanda yang menunjukan instansi, sedangkan aplikasi ini tidak dapat mengenali logo instansi tersebut jika tidak ada tulisan secara horizontal mengenai instansi tersebut. Hal ini karena Jaro-Winkler Distance merupakan algoritma pencocokan string yang hanya akan menganalisas data jenis string [2]. Beberapa kartu nama yang memakai logo instansi, seperti BNN (Badan Narkotika Nasional), BPS (Badan Pusat Statistik), Radio Papeja, Polda, dan Radio B-One.

Berdasarkan hasil ujicoba yang dilakukan selama lima kali proses ekstraksi dan pengelompokan didapatkan nilai akurasi seperti pada Tabel 4.

Table 4. Data Akurasi

\begin{tabular}{|l|c|c|c|r|r|r|r|r|}
\hline No & Perco & \multicolumn{7}{|c|}{ Nilai Akurasi (dalam \%) } \\
\cline { 3 - 10 } & baan & N & J & I & NP & NT & A & E \\
\hline 1. & 1 & 76 & 74 & 56 & 82 & 86 & 78 & 86 \\
\hline 2. & 2 & 76 & 74 & 56 & 82 & 86 & 78 & 90 \\
\hline 3. & 3 & 76 & 74 & 56 & 82 & 86 & 78 & 90 \\
\hline 4. & 4 & 76 & 74 & 56 & 82 & 86 & 78 & 88 \\
\hline 5. & 5 & 76 & 74 & 56 & 82 & 86 & 78 & 86 \\
\hline \multicolumn{2}{|c|}{$\begin{array}{l}\text { Rata }- \\
\text { rata }\end{array}$} & 76 & 74 & 56 & 82 & 86 & 78 & 88 \\
\hline
\end{tabular}

Keterangan :

$$
\begin{aligned}
& \text { N = Nama } \\
& \text { J = Jabatan } \\
& \text { I = Instansi } \\
& \text { NP = Nomor Ponsel } \\
& \text { NT = Nomor Telepon } \\
& \text { A = Alamat } \\
& \text { E = E-mail }
\end{aligned}
$$

Nilai akurasi merupakan persentase data yang benar berbanding dengan keseluruhan data sehingga rumus menghitung akurasi seperti pada rumus 5.1.

$$
\text { akurasi }=\frac{\text { data yang benar }}{\text { keseluruhan data }} \times 100 \%
$$

\section{Kesimpulan}

Berdasarkan hasil dan pembahasan yang telah dijabarkan sebelumnya, maka kesimpulan yang dapat diambil adalah sebagai berikut:

1. Aplikasi konversi teks telah dapat melakukan konversi teks kartu nama dengan melakukan ekstraksi teks dari foto kartu nama menggunakan Optical Character Recognition (OCR) dengan library Tesseract Tess-Two berbasis mobile android.

2. Aplikasi ekstraksi teks telah dapat melakukan pengelompokan data hasil ekstraksi nama, jabatan, instansi, nomor ponsel, alamat pertama, alamat kedua, nomor telepon pertama, nomor telepon kedua atau fax dan e-mail dengan menggunakan algoritma JaroWinkler Distance dengan menggunakan library Apache Commons Lang yang keseluruhan data yang telah dikelompokan dapat disimpan di dalam database smartphone. 
3. Ujicoba 50 data sebanyak lima kali proses ekstraksi dan pengelompokan menghasilkan nilai akurasi ratarata untuk data nama sebesar $76 \%$, data jabatan sebesar $74 \%$, data instansi sebesar $56 \%$, data nomor ponsel sebesar $82 \%$, data nomor telepon sebesar $86 \%$, data alamat sebesar $78 \%$, dan data email sebesar $88 \%$.

Berdasarkan analisa dan perancangan sistem, implementasi, dan pengujian sistem, maka saran yang dapat diberikan untuk pengembangan penelitian selanjutnya adalah sebagai berikut:

1. Pada penelitian berikutnya dapat menggunakan library OCR versi yang berbeda agar dapat mengidentifikasi teks berdasarkan kolomnya.

2. Pada penelitian ini database ciri-ciri instansi untuk mengenali instansi masih terbatas sehingga masih terdapat beberapa instansi yang belum dikenali, pada penelitian berikutnya peneliti dapat merancang antarmuka pengguna yang dapat memungkinkan pengguna untuk memasukan database untuk instansi.

3. Pada penelitian ini beberapa nama jalan yang gagal dikenali $100 \%$ saat proses ekstraksi membuat data alamat seringkali tidak terbaca, pada penelitian berikutnya peneliti dapat menambah database namanama jalan yang ada di kota Bengkulu.

4. Peneliti dapat menambah data training dan metode pengenalan logo-logo instansi pemerintah atau swasta agar pengenalan instansi dapat lebih mudah dikenali saat proses ekstraksi dan pengelompokan data.

5. Pada penelitian ini, peneliti tidak membuat proses preprocessing terhadap citra uji kartu nama dan hanya menggunakan tools tesseract yang terdapat di dalam library Tesseract Tess-Two sehingga ketika dilakukan proses recognition untuk mengekstraksi teks, beberapa teks masih tidak dikenali, terutama bagi kartu nama yang mengandung banyak gambar. Pada penelitian berikutnya disarankan dapat dilakukan preprocessing terlebih dahulu, seperti thresholding, skewing, rotation, atau proses lainnya untuk memperbaiki kualitas citra uji dengan menggunakan tools leptonica yang juga terdapat di dalam library Tesseract Tess-Two atau menggunakan tools lainnya.

\section{Daftar Pustaka}

[1] R. Mithe, S. Indalkar and N. Divekar, "Optical Character Recognition," International Journal of Recent Technology and Engineering (IJRTE), pp. 7275, 2013.

[2] A. Kurniawati, S. Puspitodjati and S. Rahman, "Implementasi Algoritma Jaro-Winkler Distance untuk Membandingkan Kesamaan Dokumen Berbahasa Indonesia," Universitas Gunadarma,
Depok, 2012.

[3] D. Ratliff, "Using Business Cards to Market Yourself While Job-Hunting," 1999. [Online]. Available: http://www.accuratewriting.com/businesscard.shtml.

[4] H.-C. Jeske, W. Lederer, I. Lorenz, C. Kolbitsch, J. Margreiter, J. Kinzl and A. Benzer, "The Impact of Business Cards on Physician Recognition After General Anesthesia," ECONOMICS AND HEALTH SYSTEMS RESEARCH, pp. 1262-1264, 2001.

[5] I. D. P. Manurung, A. Hidayatno and B. Setiyono, "Pengenalan Teks Cetak Pada Citra Teks Biner," Universitas Diponegoro, Semarang, 2011.

[6] R. Smith, "An Overview of the Tesseract OCR Engine," in Proc 9th Int.Conf.on Document Analysis and Recognition, 2007.

[7] X. D. Coster, C. D. Groote, A. Destine and P. Deville, "Mahalanobis distance, Jaro-Winkler distance and nDollar in UsiGesture," Université catholique de Louvain, Louvain-la-Neuve, 2011.

[8] A. Kay, "Tesseract: an Open-Source Optical Character Recognition Engine," Linux Journal, 2007.

[9] M. Heliński, M. Kmieciak and T. Parkoła, "Report on the Comparison of Tesseract and ABBYY FineReader OCR Engines," National Library of the Netherlands, Den Haag, 2011. 